\title{
PROBLEMÁTICAS EXISTENCIAIS E MODERNIDADE DE HÚMUS DE RAUL BRANDÃO
}

Resumo: O presente ensaio apresenta uma releitura de Húmus de Raul Brandão centrada nas problemáticas existenciais que atravessam o mencionado texto, sublinhando o trajeto de modernidade que o mesmo prefigura, articulando-o com temáticas e questionamentos de ordem filosófico-antropológica que o século XX desenvolveria. Assim, o pendor metafísico da obra desdobra um conjunto de intuições próprias das filosofias ditas da existência, radicando na ambígua relação com o divino, gerando o pressentimento de uma angústia existencial que implica uma autoexigência de configuração de um sentido que oblitere ou supere a consciência agónica do tempo, sentido que a relação erótica (não) concretizaria. A fragmentação textual, a propensão repetitiva e circular da narrativa, a presentificação, a polifonia, as dilações e omissões discursivas constituem estratégias textuais de desafio à lógica destrutiva do tempo linear tendente ao nada que esta ordem metafísica instaura. O dito desafio, sendo invariavelmente fracassado, acaba ainda assim por derivar numa proposta ética da resiliência face à morte, da elevação da vida como valor, que justifica o cunho pré-existencialista de Raul Brandão e dá o tom da sua modernidade.

Palavras-chave: Raul Brandão; modernidade; filosofias da existência; Deus; percurso identitário.

\section{EXISTENTIAL PROBLEMS AND MODERNITY OF RAUL BRANDÃO'S HÚMUS}

\begin{abstract}
This essay presents a rereading of Raul Brandão's Húmus centered on the existential problematics permeating the aforementioned text, underlining the path of modernity that it prefigures, articulating it with themes and questions of philosophical and anthropological order that the twentieth century would develop. Thus, the metaphysical focus of the work unfolds a set of intuitions typical of the so-called philosophies of existence, rooting in the ambiguous relationship with the divine, generating a feeling of existential angst that implies a configuration of self-demand that obliterates or overcomes the agonizing awareness of time, sensing that the erotic relationship (does not) materializes. The textual fragmentation, prone to a repetitive and circular narrative, the presentification, the polyphony, the deferments and discursive omissions constitute textual strategies to challenge the destructive logic of linear time tending to the nothingness that this metaphysical order establishes. The mentioned challenge, invariably frustrated, derives, nevertheless, into a proposal of resilience in the face of death, the rise of life as a value, which justifies the pre-existentialist nature of Raul Brandão and sets the tone for its modernity.
\end{abstract}

Key-words: Raul Brandão; modernity; philosophies of existence; God; identitary course.

\footnotetext{
1 Doutorando em Literatura pela Universidade de Évora (Portugal), com um projeto financiado pela Fundação para a Ciência e a Tecnologia. Investigador do Centro de Estudos Comparatistas (Universidade de Lisboa).
} 
A novelística novecentista de Raul Brandão (1867-1930), que o situa numa dimensão pós-naturalista, rasura os preceitos realistas de um exacerbado otimismo que não se coadunaria com uma temática metafísica e subjetivista, própria de uma problematização existencial, que uma obra como Húmus (1926) anunciaria. Esta estabeleceu-se, no âmbito da literatura portuguesa, como um poioumenon (FOWLER, 1982: 123), desafiando o conceito de género literário que a tradição lhe impôs, respondendo à crise do paradigma positivista, com a sua omnisciência e a sua tendência tética ${ }^{2}$. O que em Húmus manifesta uma inclinação para o cruzamento do romance com o ensaio cauciona outrossim uma evolução temática e formal que antecipa o romance do absurdo e o nowveau roman ${ }^{3}$. Recusando desse modo a confiança na estrutura romanesca habitual, o texto brandoniano espelha formalmente uma preocupação temática que o aproxima dos tópicos metafísicos e sociais de um Dostoiévski, integrando um elemento populista que sanciona a ideologia burguesa oitocentista (FERREIRA, 1995, p. 273), recuperando em certa medida os pressupostos individualistas que o romantismo lhe legara e em cuja persistência ancora a admiração de que foi objeto por parte dos autores da Renascença Portuguesa, e muito em particular de Pascoaes. O seu singular empreendimento geraria, desde logo, os primeiros e mais acabados exemplares de um Expressionismo praticamente desconhecido em Portugal, bem como de um protoexistencialismo cuja precocidade não poderia ser à época devidamente reconhecida, concretizada numa composição dilemática da existência. Nela encontraremos o conjunto de características que consubstanciam as conquistas e hesitações do romance novecentista (GULLÓN, 1984, p. 39), tais como uma obstinada interiorização focal, mediante uso da corrente da consciência e do monólogo interior, da coerência do ponto de

\footnotetext{
2 A mencionada dimensão rutural da sua produção justifica uma admiração que se tem adensado, e que encontrou em recetores tão privilegiados como Vergílio Ferreira, David Mourão-Ferreira e Jacinto do Prado Coelho, o eco da sua modernidade: "Na oscilação indicada, na atracção de valores contraditórios, na tentativa de criar um novo tipo de novelística, obviamente Raul Brandão teria de muitas vezes falhar. Mas que dele só ficasse um dos momentos geniais do nosso teatro, que é O Doido e a Morte, o poema maravilhoso de luz e ternura que é Os Pescadores e o indicativo do que poderia ter sido um profundo e novo romance existencial, como é o Húmus, e Raul Brandão seria já um dos mais originais e poderosos escritores de toda a língua portuguesa" (FERREIRA, 1991, p. 215); "Húmus é um texto tão denso e perturbante para a literatura portuguesa como é o Livro do Desassossego (1982). São duas obras-primas da literatura europeia, que marcam entre nós o século XX. Ambas indecisas na fixação da sua textualidade ou arquitectura, e no entanto ambas abrindo um novo espaço no curso da modernidade" (COELHO, 1969, p. 4).

3 Segundo David Mourão-Ferreira, são aspectos que introduzem o nouveau roman "o sistemático desmantelamento da intriga tradicional; a substituição de um 'espaço' realisticamente definido por um 'espaço' indiferenciado, ou neutro, ou ambiguamente simbólico; a liquidação das personagens, quer em benefício de um narrador omnipresente, quer em proveito de uma matéria cada vez mais amorfa, ou mais caótica, ou mais abstracta" (MOURÃO-FERREIRA, 1969, p. 122).
} 


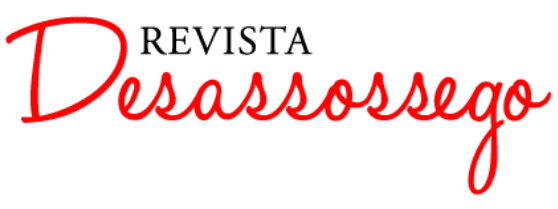

vista, da simultaneidade narrativa, bem como uma rutura da linearidade temporal teleológica.

O que de mais relevante Brandão nos legou resulta do anúncio de uma problemática existencial que Húmus acentua e cujo teor metafísico sobredetermina, instrumentalizando-a, uma problemática socioeconómica que lhe é afim ${ }^{4}$. A preponderância da problemática existencial radica, em Húmus, na ambígua e inquieta relação com o divino, questionamento a um tempo epistemológico e ontológico que determina a evidenciação de uma situação de desamparo que projeta o percurso da angústia para um sujeito implodido no âmbito das suas próprias condições limitantes:

A questão suprema é esta e só esta: Deus existe ou Deus não existe. Se não há Deus, a vida, produto do acaso, é uma mistificação. Aproveitamo-la para satisfazer instintos e paixões. Se Deus não existe, não há força que me detenha. Não há palavras, nem regras, nem leis. Tudo é permitido (BRANDÃO, 2003, p. 72).

A ausência de Deus introduz uma experiência da remoção da telicidade outrora subjacente à existência humana:

Tenho necessidade de Deus, como do ar que respiro. Sem Ele a vida é desconexa e atroz; pior, é monstruosa (BRANDÃO, 2003, p. 91).

Mas se Deus não existe - se Deus não existe que me fica no mundo? Sou nada no infinito. Fui tudo - e sou nada (...) Se Deus não existe tanto faz gritar como não gritar. Não tenho destino a cumprir: saio do nada para o nada (BRANDÃO, 2003, p. 92).

A evidência de se ser, nesta ótica, um intervalo entre dois nadas retira ao sujeito um horizonte de plausibilidade e consequencialidade existencial, mergulhado como está num sentimento de ruínas que é o resto de um mundo despojado da possível transcendência das condicionantes deíticas eu-aqui-agora. Cursando desse modo um dos tópicos fundamentais das filosofias da existência, Raul Brandão reconhecia assim a impossibilidade vertida em plausível da morte de Deus, cuja concretude gera nele um pressentimento daquilo a que viríamos, de acordo com Camus, a chamar o absurdo. Perante o horizonte de absoluta nadificação do ego, o indivíduo vê-se forçado a enfrentar "o horrível silêncio atroz"

4 Conforme observou Vergílio Ferreira, "o anúncio de uma filosofia, que lhe veio decerto de Dostoiévski, bastou-lhe para que ele fosse entre nós o primeiro ficcionista de 'ideias', nos desse o primeiro esboço do que vulgarmente se vai já chamando o 'romance-ensaio', ou, como prefiro - e disse - 'romance-problema"' (FERREIRA, 1991, p. 195-196). 
(BRANDÃO, 2003, p. 144), o pascaliano éffroi perante o silêncio dos espaços infinitos, de acordo com o qual, numa desesperada ambiguação do problema religioso, se concatena ainda um discurso acusatório: "Acuso-te de teres comprometido a minha situação no Universo (...) Acuso-te de me deixares sozinho com este peso em cima, com a ideia da vida e com a ideia da morte" (BRANDÃO, 2003, p. 144). Perante uma situação de desamparo que, segundo Lukács (1963), assinala a diegese moderna, surge a necessidade de fixar no mundo de súbito desorganizado um outro valor orientador. Assim, aproximandose da perspetiva kierkegaardiana, a evidência da morte como limite maior do eu é vertida em interrogação sobre o significado da vida, como aquilo que faz desta um destino:

Descobrir que a morte não é inevitável endurece. O mundo muda de aspecto. Agora é que eu contemplo a vida - e me perco na vida. Começo a ter medo de mim mesmo e não me posso olhar sem terror. Que é isto, este sonho, esta dor, esta insignificância entre forças desabaladas? Onde hei-de pôr os pés? (BRANDÃO, 2003, p. 55-56)

A permanência da intromissão do sagrado no quotidiano revela assim que o homem realizado é aquele que ascende à sua própria transcendência. ${ }^{5}$ A urgência de um valor que sustente a existência individual - "Sem crer não sou nada - sem crer não existo sem crer não compreendo a vida. Preciso de caminhar para um destino" (BRANDÃO, 2003, p. 92) - depara com um despojamento do sentido, prefigurado por uma retórica da inconsequência e do bloqueio - "Uma vila encardida - ruas desertas - pátios de lajes soerguidas pelo único esforço da erva - o castelo - restos intactos de muralha que não têm serventia: uma escada encravada nos alvéolos das paredes não conduz a nenhures" (BRANDÃO, 2003, p. 9, sublinhados meus) - de que a morte é metástase fulcral. Surgindo desse modo como um problema de configuração da split personality, a morte anula a telicidade, abrindo espaço ao desejo de preservação da consciência do próprio eu que aquela corrompe:

Se não existe outra vida, pergunto para quê? (BRANDÃO, 2003, p. 64) Então para que nasci? Para ver isto e nunca mais ver isto? Para adivinhar um sonho maior e nunca mais sonhar? (BRANDÃO, 2003, p. 41)

Sei que tudo são aparências, com uma única realidade, a morte. Para morrer não valia a pena viver. (BRANDÃO, 2003, p. 64)

\footnotetext{
${ }^{5}$ Conclui-se assim que "seja qual for o grau de des-sacralização do mundo a que tenha chegado, o homem que optou por uma vida profana não consegue abolir completamente o comportamento religioso" (ELIADE, 1999, p. 37).
} 
Ancorada num quase pessimismo, à maneira de Schopenhauer, a narrativa brandoniana constitui, nesta perspetiva um discurso sobre o absurdo, relatando o impossível do sonho do homem, que persegue indefinidamente a sombra de si mesmo, para nunca alcançá-la, existindo para nada. Uma série de mitemas apocalípticos configura assim uma metafísica da dor (LOPES, 1970, p. 189), em que a morte, interpretada na sua radicalidade, emerge como limite maior da vida, circularmente obstinada, conferindo o tom de abertura e de encerramento do texto: "Ouço sempre o mesmo ruído de morte que devagar rói e persiste...” (BRANDÃO, 2003, p. 9); “Aqui não andam só os vivos - andam também os mortos (...) Debalde todos os dias repelimos os mortos - todos os dias os mortos se misturam à nossa vida" (BRANDÃO, 2003, p. 24). A perspetiva da morte conforma uma experiência que enfoca "les particularités du monde fini à l'exigence éthique infinie" (SZONDI, 1975, p. 188), de um sujeito que se sabe a um tempo necessariamente imortal, para cumprir-se em profundidade, e fatalmente perecível, porque despojado de si mesmo em superficialidade. Considerando o sartriano sentido futurante do humano, e se existir é uma abertura a possíveis, tal como sustenta Heidegger, a clausura num horizonte limitado, num corpo em que se morre, faz da Weltanschanung brandoniana uma disposição que passa a assentar grosso modo nas categorias do temporal e do eterno. Uma consciência agónica do tempo motiva por conseguinte a angústia, produto da vocação de absoluto, do transcendente investido na limitação da finitude configurada por uma série de condicionantes que se impõem à condição humana.

Porque "o fim lógico da vida não é morrer, é viver sempre, é ascender sempre" (BRANDÃO, 2003, p. 41), a morte apresenta-se ao eu como inverosimilhança: "É estúpida. Primeiro é estúpida, depois é incompreensível” (BRANDÃO, 2003, p. 40); "Na realidade morrer é absurdo. Nunca me capacitei a sério que tivesse de morrer. Morrer é estúpido” (BRANDÃO, 2003, p. 35). A vivência agónica do tempo -

Bem sei. Aquilo a que me apego é impalpável: é a mulher que passou, assomando-lhe ao focinho uma expressão de ternura, e que nunca mais tornarás a encontrar; é aquela manhã de chuva em que nos molhámos juntos (e ainda me sinto molhado) e que se não repete, é o minuto que nos escorre das mãos como um fio de água, mas doura-o o sol, e é esse mesmo minuto translúcido que quero tornar a viver, sem a sombra da morte a meu lado (BRANDÃO, 2003, p. 39). 
- projeta assim uma temporalidade configurada ao modo bergsoniano que insiste num tempo não mensurável ou inerte, mas num tempo vivo, numa durée cuja densidade é a angústia, agudizada pelo facto de o próprio tempo resistir ao eu, como fenómeno inconceptualizável. Se o tempo "mói a ambição e o fel e torna as figuras grotescas" (BRANDÂO, 2003, p. 16), instaura para o sujeito uma evidência do tédio de viver para nada: "Silêncio. Ponho o ouvido à escuta e ouço sempre o trabalho persistente do caruncho que rói há séculos na madeira e nas almas" (BRANDÃO, 2003, p. 10). Gerando assim um horizonte vazio que é aborrecimento, a celeste eternulidade de que falava Laforgue (2011) -

Sempre as mesmas coisas repetidas, as mesmas palavras, os mesmos hábitos (BRANDÃO, 2003, p. 15).

Como a vida esplêndida é aborrecida e inútil! Não se passa nada, não se passa nada. Todos os dias dizemos as mesmas palavras, cumprimentamos com o mesmo sorriso e fazemos as mesmas mesuras (BRANDÃO, 2003, p. 16).

- a abundância das condições limitantes faz da existência uma reflexão do tedium vitae do eu perante o absurdo, do sem-sentido de uma existência a-télica: "como este único minuto com a morte pela eternidade pesa!” (BRANDÃO, 2003, p. 16).

Dito aborrecimento, que encontra em Heidegger (1967, p. 45) um fiel relatador, resulta fundamentalmente da morte consciencializada que liga em definitivo o sujeito ao absurdo da sua própria existência, na perspetiva que viria a ser a de Camus. ${ }^{6}$ Gerando desse modo um pressentimento da desesperança da condição humana, a consciência do eu, como consciência da limitação que lhe está inerente, faz do homem, na fórmula unamuniana, um animal doente. Assim, e porque "só o homem morre, porque sabe que morre" (BRANDÃO, 2003, p. 245), a consciência permite-lhe objetivar, mais ou menos imperfeitamente, o semsentido do seu projeto - "A vida foi um nada, impregnou-os para toda a eternidade: um instante de luz bastou para lhes dar gosto à dor" (BRANDÃO, 2003, p. 105) - que nenhuma revolta poderá conter ou vingar:

E por mais que grite, por mais que proteste, estou aqui diante do incompreensível, vivo ou nada, de pé na voragem. E para lá há uma coisa infinita, um negrume infinito, uma vida infinita. Só deparo na minha

6 "Un homme devenu conscient de l'absurd lui est lié pour jamais. Un homme sans espoir et conscient de l'être n’appartient plus à l'avenir”' (CAMUS, 1942, p. 35). 


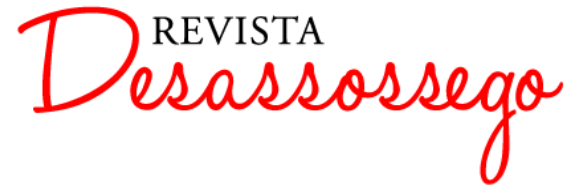

frente com infinito sobre infinito, com o negrume sufocado, com o negrume impassível, com o negrume vivo e imenso, desesperado e imenso (...) Estou aqui defronte do espanto e sinto-me perdido na vastidão infinita. Tudo o que disse - disse-o diante do vácuo, tudo o que sofri - sofri-o diante do vácuo, todo o meu desespero, a minha dor, a renúncia, os esforços, o calvário - diante do vácuo! (BRANDÃO, 2003, p. 93)

É nesta perspetiva que a obra brandoniana antecipa a Grundbefindlicbkeit heideggeriana, através da qual o sujeito pressente a morte não já como um dado mas como uma negatividade, como uma falta de ser. É onde esta se converte em a priori (SCHELER, 1968) ou num interior à vida (SIMMEL, 1986). A experiência da interiorização do tanatológico configura uma meditatio mortis, segundo a qual a morte não representa já apenas um factum mas ainda um interpretativum, através de uma inevitável consciencialização antecipadora da sua realidade que lhe confere um valor apofântico. A vida, assim feita sub specie mortalis - "O problema capital da vida é o problema da morte" (BRANDÃO, 2003, p. 128) - faz da narrativa uma necessária procura do sentido contra a inverosimilhança de um mundo desprovido de telicidade - "se a vida futura é um absurdo, esta vida é um absurdo maior” (BRANDÃO, 2003, p. 65) -, conforme prefigurado pela obsidiação da presença da morte: "Se me perguntam o que é a vida - não sei o que é a vida. Sei que me devora - sei que tenho ao pé de mim a morte" (BRANDÃO, 2003, p. 64); "É que a morte regula a vida. Está sempre ao nosso lado, exerce uma influência oculta em todas as nossas acções" (BRANDÃO, 2003, p. 47). Deste modo, também para Raul Brandão a aitiologia depende da teleologia, segundo o conceito heideggeriano de projeção (Entwurf), mediante a exploração de uma existência referida ao sentido. Assim, a morte não constitui um problema em si mesmo, mas, como para as filosofias da existência, um modo de exigir que a vida se cumpra como destino: "Ela não entra, pois, no questionário de Raul Brandão senão como um espelho imprevisto que nos ergue a imagem de nós próprios" (FERREIRA, 1995, p. 274). Esta meditação sobre a condição humana face à finitude é concretizada individualmente como um problema da carência da identificação do eu a si mesmo que o sem sentido de aquele existir para a morte agudiza. Dessa forma, a questão da morte constitui o mote para uma problematização da identidade própria: "Juntem a isto a Morte e aquela voz de desespero cada vez mais frenética, que não cessa de pregar, e que me põe em frente de mim mesmo, que é o que mais temo no mundo" (BRANDÃO, 2003, p. 37). Assim, compreendendo com Heidegger (1993, p. 267) que "mal o homem entra na 
vida é suficientemente velho para morrer", nasce na narrativa brandoniana um total cuidado do eu, próprio do platónico epimelai beautou (FOUCAULT, 1984), que lança ainda a proposta de uma bybris contra esse "muro que é forçoso deitar abaixo" (BRANDÃO, 2003, p. 57).

O egografismo de Húmus, mediante a radicalização do subjetivismo temático e percetivo que o assinala, centraliza o problema da personalidade. A dialogicidade do eu a si mesmo postula uma espécie de ironia trágica, conforme teorizada por Schlegel, que dá conta da "awareness of the limitations of the self" (MELLOR, 1980, p. 10). Funcionando desse modo como autoironia (SCHOENTJES, 2001, p. 186-188), problematizando a conceção do eirôn, a ironia assinala, por conseguinte, uma disposição subjetiva (GROSOS, 2009, p. 95). Esta forma de ironia pós-socrática, subjetivada, encontra assim em Raul Brandão um dos seus máximos cultores, numa interrogação sobre os limites do Homem, sobre o intervalo que se instala entre o seu projeto e a sua concretude, presente em Húmus, dando conta da discordância entre a dimensão real da existência individual e a dimensão ideal da mesma, entre um nada e um tudo, faces coevas da khrisis irónica. Entre o ilimitado e o limitante nasce a experiência ironizada, portadora da angústia, dado que "l'homme ne se perçoit plus comme une unité homogène mais comme un assemblage sous tension d'éléments contradictories" (SCHOENTJES, 2001, p. 111). Este carácter tensional, próprio da conceção romântica da ironia como "something like a human condition or predicament" (COLEBROOK, 2004, p. 48), revela a experiência existencial na sua paradoxalidade, sob a configuração de um "indissoluble antagonism between the absolute and the relative" (SCHLEGEL, 1991, p. 13) ${ }^{7}$. Uma certa não coincidência do homem consigo mesmo, que Ricoeur (1988, p. 21) identifica com o mal, projeta um sentimento angustiado decorrente de dimensão trágica do absurdo anexado ao destino do sujeito, "the contrast between man with his hopes, fears, wishes, and understandings, and a dark, inflexible fate, affords abundant room for the exhibition of tragic irony" (MUECKE, 1970, p. 21).

Tendo como cenário uma vila fantasmagórica e burlesca, cujo substrato disfórico é evidente, procede-se assim a um original desdobramento do narrador em instância a um tempo enunciadora e agente (através de Gabiru), numa rutura formal sem precedentes,

\footnotetext{
${ }^{7}$ A ironia trágica relata, assim, uma cisão interior, de que a definição de Szondi dá um acabado espelho: "Le sujet de l'ironie romantique est l'homme isolé, devenu son propre objet et privé par la conscience de la puissance d'agir. Il aspire à l'unité et à l'infinitude, et le monde lui apparaît fissuré et finil' (SZONDI, 1975, pp. 108-109).
} 
expondo desse modo a duplicidade inerente ao sujeito. A realidade, na sua banalidade quotidiana, oblitera a dimensão projetiva do eu - "Sob estas capas de vulgaridade há talvez sonho e dor que a ninharia e o hábito não deixam vir à superfície" (BRANDÃO, 2003, p. 9-10) -, letargicamente mergulhado nas relações comezinhas com o espaço circundante "Construímos ao lado outra vida falsa, que acabou por nos dominar" (BRANDÃO, 2003, p. 18). Com efeito, e conforme observa Vergílio Ferreira, na perspetiva de Raul Brandão, “atrás da realidade imediata há a irrealidade e essa é que lhe é a verdadeira realidade, e que à dita 'realidade' ilumina" (FERREIRA, 1991, p. 185), recordando desse modo a dualidade ontológica kierkegaardiana ${ }^{8}$. Por esse motivo, José Carlos Seabra Pereira (2004, p. 269) poderia afirmar que "toda a obra de Raul Brandão vive em regime paroxístico e contrapolar ou ambivalente", que nele predomina a "dialéctica do patético com o grotesco, do belo ideal com o repulsivo, do sublime com o horror físico e moral". Essa ambivalência resulta da revelação da insuficiência da realidade limitante para um sujeito que se deseja ilimitado, no que faz da vida "um simulacro" (BRANDÃO, 2003, p. 23) ${ }^{9}$. A presença daimoníaca do outro que nos habita encontra aqui um dos mais desconcertantes relatos - "Tu lutas contra esta figura que dentro de ti te impele; tu queres fugir de ti próprio, queres separar-te de ti mesmo, e não podes" (BRANDÃO, 2003, p. 175) -, denunciando a dimensão patológica da submissão do pulsional à mediação da convencionalidade:

Mais de metade, muito mais de metade dos meus sentimentos, são postiços. Todos estamos ligados por compromissos, aceitamos certas leis e vivemos de aparências (BRANDÃO, 2003, p. 136).

Para podermos viver só lidamos com uma parte convencional da vida (...) No princípio só fomos almas, criámos depois a casca (...) Éramos todos fantasmas. Criámos tudo - e a mentira. Tudo - e o hábito. Tudo e a paciência (BRANDÃO, 2003, p. 136-137).

Pese embora o engendramento do quotidiano como estratagema de divértissement, no sentido pascaliano do termo, o eu projetivo, que o concreto dissimula -

\footnotetext{
8 "Detrás del mundo en que vivimos, en un fondo lejano, hay otro mundo que guarda con el real una relación similar a la que existe entre la escena teatral y la escena de la realidad, barruntada a través del arte escénico. Mediante una sutil niebla, contemplamos aquel mundo nebuloso, más tenue, más etéreo y de calidades muy diversas a este mundo real" (KIERKEGAARD, 1976, p. 185).

9 Nesta perspetiva, Jacinto do Prado Coelho afirma que "o homem descobre o absurdo na sua própria duplicidade, melhor, na disputa de elementos contraditórios que o solicitam; descobre também o absurdo na aporia que o divide entre a aparência, a mediocridade falaz do quotidiano, e o abismo subterrâneo, o insondável, a vertigem" (COELHO, 1969, p. 328).
} 
O homem por dentro é desconforme. É ele e todos os mortos. É uma sombra desmedida; encerra em si a vastidão do Universo. E com isto teve de atender a máscara. Para poder viver teve de se transformar e de esquecer a figura real por a figura de todos os dias (BRANDÃO, 2003, p. 77)

- acaba por prevalecer como pressentimento especular: "há ainda outra coisa indefinida e imensa diante de mim, ao pé de mim, dentro de mim” (BRANDÃO, 2003, p. 89). A dimensão fantasmática do sujeito exacerba-se e uma interrogação fulcral inscreve-se no horizonte trágico do indivíduo: "quer então dizer que só vivi uma vida fictícia ao lado da vida e que perdi o melhor da existência em aparências?” (BRANDÃO, 2003, p. 82). A evidência do hiato irónico-trágico - "Em todas as almas, como em todas as casas, além da fachada há um interior escondido" (BRANDÃO, 2003, p. 51); “entre mim e mim interpôsse um muro" (BRANDÃO, 2003, p. 67) - converte a vida em exercício de contenção, negócio: "Todos sentimos atrás de nós um mundo, outro mundo (...) de apetites que nunca se realizaram - todos cobrimos isto de aparências. Passamos a vida a conter outro ser outra coisa - outro espanto” (BRANDÃO, 2003, p. 86).

Concretizando assim um sentimento trágico, próprio do que foi a conceção metafísica de um dos seus admiradores, Miguel de Unamuno, configura-se o conflito entre aquilo a que Hölderlin chama o aórgico e o elemento orgânico, fazendo do sujeito afundado no seu concreto, à maneira de Píndaro, o sonho de uma sombra. ${ }^{10} \mathrm{O}$ eu situa-se, portanto, em dois planos, aquele que é próprio do marginal ao real, e aquele que é próprio do dado da existência real. Como poucos soube Raul Brandão em que consiste a hegeliana consciência infeliz, forma de conflito pessoalizado entre absoluto e relativo, entre verdade e aparência. O sujeito assim dividido, incapaz de fazer coincidir ipse e idem, encontra na existência irónica uma limitação epistemológica. O Ding-an-sich kantiano esbarrará na "awareness of the limitations of the self" (MELLOR, 1980, p. 11). ${ }^{11}$ Se é certo que "el sujeto se sabe dentro de sí como lo absoluto, y todo lo demás es vano para él” (HEGEL, 1955, p. 482), a sua condição fraturada faz com que, procurando-o, encontre apenas coisas, segundo aforismo de Novalis.

\footnotetext{
${ }^{10}$ Há, com efeito, em Raul Brandão, a antecipação de um certo surrealismo pela fusão de sonho e realidade (FERREIRA, 1995; COELHO, 1969).

11 Prossegue Mellor, referindo-se à "inevitable and all-important consciousness of the limitations of human knowledge and of human language” (MELLOR, 1980, p. 11).
} 
Há, não obstante, instantes em que emerge um esquema suspensivo, nos quais se lança "um grito que não se extingue", de pendor extático perante a e-vidência revelacional do eu a si mesmo: "Nesse momento de paixão todas as forças se concentram e ponho o pé no mistério" (BRANDÃO, 2003, p. 90). Esse instante revelacional, que se associa à Offenbarung schopenhaueriana, no seu carácter projetivo e fugaz, identificado como está com o prazer (AGAMBEN, 2011), permite uma vivência em profundidade - "E percebi o Universo como força e destino a tal profundidade, que nesse rápido segundo passou por mim numa rajada todo o turbilhão da vida, com as suas vozes, os seus mistérios e toda a sua grandeza feroz" (BRANDÃO, 2003, p. 70) - acedendo dessa forma a uma espécie de dimensão cairológica do tempo, como profundidade que aponta para a eternidade ${ }^{12}$, como temps transcendant, na concepção de Parrett ${ }^{13}$ : "Há em todas as existências alguns segundos em que sentimos o contacto do mistério - de que nos separam logo léguas e impenetrabilidade" (BRANDÃO, 2003, p. 178). A fugacidade de dito instante retoma o sentimento disfórico, e agrava-o, fazendo com que o desejo de re-coincidência do eu a si mesmo encontre na teleologicidade típica da orientação cronológica da existência uma condição limitante da projeção da plenitude do Homem. Por esse motivo, a revelação do eu a si mesmo é também a revelação de que esse instante, como tal, nunca se repetirá: "Nunca mais outro segundo igual nem na luz, nem na vibração, nem na ternura... O momento em que me sorriste, baloiçado entre o nada e o nada, nunca mais se tornaria a repetir, idêntico e completo" (BRANDÃO, 2003, p. 177). Motivo privilegiado do acesso do eu a si mesmo é a iminência do amor como adesão ao privilégio de um milagre: "O amor é um único minuto. Um minuto esplêndido" (BRANDÃO, 2003, p. 174). Como absoluto de vivencialidade, a relação amorosa transforma-se em mutuocidade revelacional, experiência da re-unificação do eu ao todo. Por essa via, o amor é, em Raul Brandão, um modo de reconhecer um destino coletivo, de uma condição que fundamenta a comunhão na solidariedade, relativa à figura popular integrada num horizonte não tanto socioeconómico, mas moral. O pobre de Raul Brandão é assim o povo alheado do seu pitoresco, como

\footnotetext{
${ }^{12}$ Neste sentido afirma Merleau-Ponty que "no meu presente, se o capto ainda vivo e com tudo o que ele implica, há um êxtase para o futuro e para o passado que faz aparecer as dimensões do tempo, não como rivais, mas como inseparáveis: ser no presente é ser de sempre e para sempre" (MERLEAU-PONTY, 1945, p. 483).

13 'J'appelle ce troisième Temps: Temps ambiant ou Temps-sphère. Ce Temps est sphérique: non plus une ligne, mais un cercle, non pas un cercle fermé mais un cercle en propension, une 'couronne' en propensions vers l'infini" (PARRET, 1995, p. 56-57).
} 
portador da angústia que pode, em instantâneos fugazes, converter-se cristicamente em beleza ou iluminação, num miserabilismo patético afim de Hugo.

Perante a desorientação do sujeito lançado num mundo desconexo, a narração brandoniana só poderia expressar concomitantemente uma aparente desordem enunciativa. A flutuação da organização interna fica patente pela abundância de repetições, retornos e ambiguidades ao longo de todo o Húmus, no que nele é da ordem de uma mescla de ensaio, diário e romance. Procedendo desse modo a uma descronologização que uma memória inventiva opera através da presentificação, tendo em vista uma possível resolução da dualidade irónico-trágica, as dilações e omissões apresentam não apenas uma função narrativa mas também temática, concretizando formalmente o desejo de um absoluto existencial que configure um sentido possível para uma existência fragmentária. Como força resistiva, que detém a passagem do tempo, o texto, manipulando as instâncias cronotópicas, reitera o carácter projetivo da face ideal do eu do autor por sobre o texto, em que se suspende o tempo de inquietação e se impõe um tempo de fruição. É onde escrever é "se livrer à la fascination de l'absence de temps" (BLANCHOT, 1988, p. 128), através do recurso ao estatismo cronológico da presentificação, dada pela anulação da explicitação das coordenadas analépticas e possibilitando a identificação de presente e passado, fazendo da memória/da fixação textual narrativa, uma realização da atemporalidade desejada. O uso do presente do indicativo acabará por unificar um aparelho ilusório de eternidade ${ }^{14}$ ou de suspensão instantânea do tempo, através do privilégio de "um tempo espesso, pesado, que se alonga até se confundir com a eternidade" (COELHO, 1969, p. 326). ${ }^{15}$ Apelando desse modo à memória re-escrita como possibilidade de retomar o evento aparicional a posteriori, vivenciando-o como se da primeira vez, a presentificação surge como o campo instrumental em que as perceções adquirem um pendor simbólico de rara intensidade.

Secundarizada deste modo a narrativa, através do sobrepujamento da construção textual por sobre a sequencialidade diegética, é esta configurada como uma forma en train de se faire, pelo que a composição formal de Húmus espelha a recusa da identificação hegeliana de verdade com a totalidade, agudizando o fragmentarismo percecional da existência e a

\footnotetext{
${ }^{14}$ Segundo Gullón, esta é uma caracterísitca própria do romance lírico, no qual "pasa el tiempo, y su pasar es el drama; para detenerlo el narrador se cita con el pasado, con el instante del pasado que el momento presente recupera. Y el tiempo narrativo es siempre el presente, pero un presente intemporalizado, como corresponde a ese 'fuera de tiempo' que es la eternidad" (GULLÓN, 1984, p. 21).

15 A capacidade de suspender o tempo através da presentificação é justamente aquilo que Vergílio Ferreira admira na obra em análise: "Em Húmus não há tempo. É à luz da eternidade que a vida aí se revela e a eternidade é imóvel (...) Húmus passa-se num instante que se prolonga” (FERREIRA, 1991, p. 221).
} 
inessencialidade da verdade postulada como inacabamento (REYNAUD, 2000). Como observa Fokkema (1988, p. 63-76), a descontinuidade, o fragmentarismo, o estatismo são marcas de um discurso alicerçado no privilégio da perceção da realidade por um narrador, por um eu, que em Raul Brandão é acentuadamente dual. Assim se abre espaço formalmente para uma figuração da patologização da vivência miserabilista, experienciada na sordidez do mundo civilizado, de inclinação decadentista, que uma reelaboração antiestetista e expressionista procura dominar. O absurdo, a inessencialidade numémica, encontra paralelo na flutuação nominal, entre Elias de Melo e Melias de Melo, Melias e Melos, Elias Melias Melambes. A permanente dualidade que assinala o sujeito encontra paralelo no sistemático recurso a antíteses, oximoros, quiasmos (REYNAUD, 2000). Associada como está essa dualidade entre concreto e projetivo à condição perecível do eu, a escrita, como instrumental demiúrgico que encerra a potencial transformação ilusória das condicionantes cronotópicas, fez com que Raul Brandão defendesse uma antropologia estética, sustentada, desde logo, numa organização circular da narração. Entendida como o derradeiro espaço topofílico, a escrita literária concebe a mecânica do acesso a um tudo que anule os limites quotidianos, criando o projeto de um espaço cósmico uno e infinito que, como observa Tadié (1978, p. 119), anularia o conteúdo da temporalidade e instalaria um outro próximo ao da circularidade do processo espiritual (Kreislauf) hegeliano: "Ainda o que nos vale são as palavras, para termos a que nos agarrar" (BRANDÃO, 2003, p. 20). A instauração de um tempo circular é assim ainda uma forma de apropriação do universo temporal e espacial pelo eu (BERTRAND, 1985, p. 122). A dissolução da estrutura cronológica linear do romance tradicional, que justifica o facto de os resultados da realização das ações infinitamente detidas no tempo como instantâneos resultarem na meia de vinte metros da prima Angélica, ou em Joana que traz um carrego à cabeça desde o princípio do mundo, retoma o vício do círculo (KLOSSOVSKY, 1969), segundo o qual o escritor recusa toda a linearidade temporal que desemboca no nada. Uma vivência disfórica da temporalidade acede desse modo à "phénoménologie du rond" de Bachelard (1984, p. 208 e ss.), que, afirmando com Jaspers que o ser é redondo, projeta o círculo como matéria sísifica, símbolo da "totalidade temporal e do recomeço"

16 Gilbert Durand acrescenta: "o círculo, onde quer que apareça, será sempre símbolo da totalidade temporal e do recomeço" (DURAND, 1989, p. 221). 
Húmus afirma deste modo o passatempo da repetição - "O que eu quero é tornar a viver. A minha saudade é esta. O que eu quero é recomeçar a vida gota a gota" (BRANDÃO, 2003, p. 37) -, forma de simulacro, tal como interpretada por Deleuze (2000), de suspender a realidade e reinstaurar o princípio. ${ }^{17}$ Deste modo, a reiteração procede à domesticação da temporalidade, mediante uma liricização da narrativa que a aproxima do domínio do sagrado ${ }^{18}$ : "Por isso existe uma certa grandeza em repetir todos os dias a mesma coisa (...) as manias têm uma força enorme, são elas que nos sustentam" (BRANDÃO, 2003, p. 23). Recusando, em geral, a frequência iterativa, Húmus prolonga indeterminadamente os dados: "Não há anos, há séculos que dura esta bisca de três - e os gestos são cada vez mais lentos. Desde que o mundo é mundo que as velhas se cruzam sobre a mesma mesa de jogo" (BRANDÃO, 2003, p. 16). Modelo resistivo que defende a vida face à morte, a escrita forja assim, em Húmus, uma inautenticidade ao modo heideggeriano, onde a estética brandoniana se faz ética. Se "chegamos todos ao ponto em que a vida se esclarece à luz do Inferno", é a própria vida que se erige como valor configurador de uma re-telicidade: "Se a vida é um momento entre o nada e o nada, o que vale a pena é aproveitá-lo" (BRANDÃO, 2003, p. 71); "Vive devagarinho. Aquece-te à réstia do sol como quem nunca mais tornará a aquecer-se; perde todas as horas a trespassar-te da vida" (BRANDÃO, 2003, p. 224) ${ }^{19}$. Trata-se assim da única verdadeira questão filosófica segundo Camus, a que Raul Brandão antecipadamente respondia: "Se vale a pena viver a vida? Só a luz! só a luz vale a vida!”. Os instantes de lucidez revelacional conquistam ao sujeito um espaço para uma felicidade - "Valeu-me a pena viver? Fui feliz, fui feliz no meu canto" - conjugada com a perceção da sua própria fugacidade: "Não sei se creio (...) na imortalidade da alma, mas no fundo do meu ser agradeço a Deus ter-me deixado assistir um momento a este espectáculo desabalado da vida". Assim, há uma ambígua superação do pessimismo pela alquimia transmutacional da dor em beleza

\footnotetext{
17 "Essa repetição, ao actualizar o momento mítico em que o gesto arquetípico foi revelado, mantém continuamente o mundo no mesmo instante auroral do princípio" (ELIADE, 1990, p. 95).

${ }^{18}$ Há, com efeito, um parentesco entre poesia e sagrado, pelo lado da temporalidade, através da estruturação da reiteração cíclica, das fórmulas da repetição: "La chaîne une fois brisée par une cyclisation qui en suspend le déroulement un éthos est produit qui s'apparente à la contemplation intemporelle” (DUBOIS, 1977, p. 124).

19 Conforme observa a este propósito Vergílio Ferreira, "quando o desespero se acalma e a vida nos fala ainda, a exaustão dessa vida, a afirmação do seu valor, que é o da beleza indiscutível dela, menos que uma convicção afirmada dir-se-ia exprimir apenas uma calma resignação” (FERREIRA, 1995, p. 275).
} 
(VIÇOSO, 1999, p. 210). É na hybris que o homem assim heroicizado encontra a sua possibilidade salvífica:

Sou nada diante do Universo. Mas teimo, mas discuto comigo e contigo ó espanto, mas defronto-me com o enigma, encarniço-me e saio daqui esfarrapado, despedaçado - mas teimo e hei-de vencer-te. Não quero morrer de vez. Não quero perder a consciência do Universo nem a sensibilidade do Universo. Eu sou o nada, tu és o Infinito - hei-de por força vencer-te (BRANDÃO, 2003, p. 128).

É nessa medida que Raul Brandão conclui da urgência de fixar o projeto de uma negação da morte, que desloca o foco ontológico e epistemológico subjacente à sua obra para uma problematização axiológica, na conversão do saber até onde sou e o que sou numa espécie de decisão existencial, ao modo jaspersiano, que responde ao para quê de tudo. Obliterado desse modo o valor da verdade e da imortalidade, emergem com primazia aqueloutros da justiça e da dignidade, que encontram, como vimos, na ficção a possível transcendência do universo limitante da verdade mortal do eu:

mas a beleza trágica da vida efémera consiste em te resistir, todo o nosso afã em criar uma mentira para opor à tua verdade (...) Tu podes tudo como verdade. Estou nas tuas mãos. Eu posso tudo como mentira, e só assim saio das tuas mãos. A verdade é a dissolução e a morte, és tu; a mentira é a vida. Resisto-te para poder viver; para poder viver crio a mentira trágica. Se cedo ao teu impulso, se escuto as tuas vozes, levas-me para uma vida inferior; se te oponho a mentira, caminho para uma via dolorosa: engrandeço-me (...) Todos os heróis são mártires (BRANDÃO, 2003, p. 192).

Contra a nadificação do eu, resta-lhe ainda decidir, conforme observava Sénancour, entre permitir que dita nadificação constitua uma expiação ou uma injustiça. E porque Raul Brandão é pela vida - "Tudo me parece inútil e agarro-me com desespero a um fio de vida, como um náufrago a um pedaço de tábua" (BRANDÃO, 2003, p. 225) - não poderia não optar pela dignitas:

Tudo neles, até o ridículo, se traduz em sofrimento, em não sei quê de superior, que lhes dá o ar, apesar de caídos, de deuses em luta com forças supremas, que, pretendendo torná-los mais grotescos ainda e reduzi-los a zero, os elevam pelo ridículo e pela dor (...) Há neste trapo que criaste, nesta coroa de lata que foi o teu sonho e a tua vida, não sei quê de imortal (BRANDÃO, 2003, p. 196). 
Numa revoltada resignação, no acolhimento resistivo dos limites, o sujeito alinha-se assim com a morte como destino que, triunfando necessariamente sobre si, confirmará nele a justiça de ter vivido e de merecer viver ainda:

Cheguei ao ponto, Morte. Cheguei onde queria. Tu és o meu sonho frenético. Não há outro maior. Cheguei ao ponto em que te não distingo da vida. Tu és a vida maior (...) Cheguei ao ponto, Morte, em que não me metes medo. Aceito-te. De ti me vem a vida. Absorve-me (BRANDÃO, 2003, p. 227).

Se "o frio da morte dá à vida um encanto superior e um prestígio maior" (BRANDÃO, 2003, p. 126), então “é a morte que faz falta à vida” (BRANDÃO, 2003, p. 229). É exatamente por negá-la o Homem que aquela se faz absurda: “Aqui há, portanto, um erro primário. Protestas do fundo do teu ser: a morte é absurda” (BRANDÃO, 2003, p. 36), pelo que é necessário perseverar no desejo - "no fundo do teu ser uma ânsia superior a tudo, que é a melhor parte do teu ser" (BRANDÃO, 2003, p. 65) -, no conatus essendi espinosista: "Se me perguntassem o que queria ser - queria ser isto mesmo. Assim na eternidade te queria, minha alma, com o mesmo sonho, com a mesma vida e os mesmos erros. Não te troco por outra alma” (BRANDÃO, 2003, p. 64). No rastro do will to believe de William James, e visando a salvação investida na própria finitude, é possível viver ainda em enthousiasmós, ter Deus dentro de si (LAGANDRÉ, 2000, p. 31 e ss.). Eis porque Raul Brandão converte em certa medida o Deus lógico no Deus biótico, destacando na sua vivência religiosa fundamentalmente a sua dimensão redencional. Colocando assim ênfase na fé como signo fundamentalmente afetivo e volitivo, expressão cordial ou intuitiva típica de São Paulo, recupera-se a máxima de Espinosa que, radicalizando a noção cartesiana de substância como aquilo que não necessita de mais nada para existir - sive substantia prepondera o desejo de perduração como essência do indivíduo agente de um apetite de eternidade, na cupiditas. A fé em Deus, e fundamentalmente a fé na própria decisão da vida do eu, converte-se assim na derradeira resposta de um texto em que a dada altura se lê um apelo que é em Raul Brandão um cunho de modernidade: "Deixem-me ir para a cova agarrado a este nada imenso, que me dourou as mãos e me deixou atónito" (BRANDÃO, 2003, p. 126). 


\section{BIBLIOGRAFIA}

AGAMBEN, Giorgio. Infancia e Historia. Trad. Silvio Mattoni. Buenos Aires: Adriana Hidalgo Editora, 2011.

BACHELARD, Gaston. La poétique de l' espace. Paris: PUF, 1984.

BERTRAND, Denis. L'espace et le sens. Paris/Amsterdam: Hadès/Benjamins, 1985.

BLANCHOT, Maurice. L'espace littéraire. Paris: Gallimard, 1988.

BRANDÃO, Raul. Húmus. Lisboa: Dom Quixote, 2003.

CAMUS, Albert. Le Mythe de Sisyphe. Paris: Gallimard, 1942.

COELHO, Jacinto do Prado. "O Húmus, de Raul Brandão: uma obra de hoje”. A Letra e o Leitor. Lisboa: Portugália, 1969.

COLEBROOK, Claire. Irony. London and New York: Routledge, 2004.

DELEUZE, Gilles. Diferença e Repetição. Trad. Luiz Orlandi e Roberto Machado. Lisboa: Relógio d'Água, 2000.

DUBOIS, Jacques. Rhétorique de la poésie: lecture linéaire, lecture tabulaire. Bruxelles: Éditións Complexe, 1977.

DURAND, Gilbert. As Estruturas Antropológicas do Imaginário. Trad. Hélder Godinho. Lisboa: Presença, 1989.

ELIADE, Mircea. O Sagrado e o Profano. A Essência das Religiões. Trad. Rogério Fernandes. Lisboa: Livros do Brasil, 1999. - O mito do eterno retorno. Trad. Manuela Torres. Lisboa: Círculo de Leitores, 1990.

FERREIRA, Vergílio. Espaço do Invisivel 4. Venda Nova: Bertrand Editora, 1995. . Espaço do Invisiviel 2. Venda Nova: Bertrand Editora, 1991.

FOKKEMA, Douwe W.. História Literária - Modernismo e Pós-Modernismo. Trad. Abel Barros Baptista. Lisboa: Vega, 1988.

FOUCAULT, Michel. A Foucault Reader. Ed. Paul Rabinow. Nova Iorque: Pantheon, 1984. FOWLER, Alastair. Kinds of Literature: An Introduction to the Theory of the Genres and Modes. Cambridge: Harvard University Press, 1982.

GROSOS, Philippe. L'ironie du réel à la lumière du romantisme allemande. Lausanne: L'Age d'Homme, 2009.

GULLÓN, Ricardo. La novela lírica. Madrid: Cátedra, 1984.

HEGEL, Georg Wilhelm Friedrich. Lecciones sobre la bistoria de la filosofía. Trad. Wenceslao Roces. México: Fondo de Cultura Económica, 1955. 


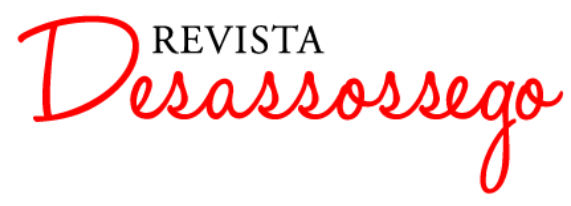

HEIDEGGER, Martin. Ser e Tempo. Trad. Márcia de Sá Cavalcante. Petrópolis: Vozes, 1993. - ¿Qué es Metafísica? Trad. Oberdan Caletti. Buenos Aires: Siglo Veinte, 1967.

KIERKEGAARD, Soren. Diario de un seductor. Temor y temblor. Trad. D. Gutiérrez Rivero. Madrid: Guadarrama, 1976.

KLOSSOVSKY, Pierre. Nietəsche et le cercle vicieux. Paris: Seuil, 1969.

LAFORGUE, Jules. Essential Poems and Prose of Jules Laforgue. Boston: Black Widow Press, 2011.

LAGANDRÉ, Cédric. L'inspiration des Grecs. Paris: L'Harmmatan, 2000.

LOPES, Óscar. "Certa filosofia da dor na sua moldura histórica". Ler e Depois. Porto: Inova, 1970.

LUKÁCS, Georges. La théorie du roman. Berlim: Éditions Gonthier, 1963.

MELLOR, Anne K.. English Romantic Irony. Cambridge/London: Harvard University Press, 1980.

MERLEAU-PONTY, Maurice. Phénoménologie de la Perception. Paris: Gallimard, 1945.

MOURÃO-FERREIRA, David. "Releitura do Húmus". Tópicos de Crítica e de História Literária. Lisboa: União Gráfica, 1969.

MUECKE, Douglas Colin. The Compass of Irony. London and New York: Routledge, 1970.

PARRET, Herman. "Réflexions saussuriennes sur le temps et le moi. Les manuscrits de la Houghton Library à Harvard“. Saussure aujourd'bui (Colloque de Cerisy). Numero Especial de LINX, Université de Paris-Nanterre: Centre de Recherches Linguistiques, 1995.

PEREIRA, José Carlos Seabra. "Introdução. Raul Brandão e o Legado do Expressionismo". História Crítica da Literatura Portuguesa. Do fim-do-século ao Modernismo. Tomo VII. Lisboa/São Paulo: Editorial Verbo, 2004.

REYNAUD, Maria João. Metamorfoses da Escrita. Húmus de Raul Brandão. Porto: Campo das Letras, 2000.

RICOEUR, Paul. Philosophie de la volonté II. Finitude et culpabilité. Paris: Aubier, 1988.

SCHELER, Max. El puesto del hombre en el cosmos. Trad. José Gaos. Buenos Aires: Losada, 1968.

SCHOENTJES, Pierre. Poétique de l'ironie. Paris: Éditios du Seuil, 2001.

SCHLEGEL, Friedrich. Philosophical Fragments. Trad. Peter Firchow. Minneapolis: University of Minnesota Press, 1991. 
SIMMEL, Georg. El individuo y la libertad. Ensayos de crítica de la cultura. Trad. Salvador Más. Barcelona: Península, 1986.

SZONDI, Peter. Poésie et Poétique de l'idéalisme allemand. Paris: Gallimard, 1975.

TADIÉ, Jean-Yves. Le récit poétique. Paris: Presses Universitaires de France. 1978.

VIÇOSO, Vítor. A Máscara e o Sonho. Vožes, Imagens e Símbolos na Ficção de Raul Brandão. Lisboa: Cosmos, 1999. 